Tohoku J. exp. Med., 1973, 111, 71-78.

\title{
Effect of Furosemide Administration and Upright Position on Plasma Renin Activity and Angiotensin II in Hypertension
}

\author{
Soitsu Fukuchi, Takahiko Takenouchi and Katsuo \\ NaKaJima \\ Department of Internal Medicine, Tohoku University School \\ of Medicine, Sendai
}

\begin{abstract}
Fukuchi, S., Takenouchi, T. and Nakajtma, K. Effect of Furosemide Administration and Upright Position on Plasma Renin Activity and Angiotensin II in Hypertension. Tohoku J. exp. Med., 1973, 111 (1), 71-78 — Both plasma renin activity and angiotensin II during recumbency measured by radioimmunoassay, were normal in essential hypertension, chronic glomerulonephritis and bilateral renal artery stenosis, definitely low in primary aldosteronism, and high in unilateral renal artery stenosis. In normal subjects upright posture and furosemide administration induced an elevation in plasma renin activity; which correlated directly with the elevation in angiotensin II. In general, the increase in plasma renin activity was much larger than that in plasma angiotensin II. Plasma renin activity and angiotensin II did not increase in primary aldosteronism, while markedly increased in unilateral renal artery stenosis during upright posture with furosemide administration. The response of plasma renin activity and angiotensin II in essential hypertension and chronic glomerulonephritis was essentially similar to that observed in normal subjects. The suppression of plasma renin activity is uniquely diagnostic of an aldosterone-secreting adrenal tumor. Similarly, the enhancing effect on plasma renin activity and angiotensin II of the upright position might be a good index for the diagnosis of renovascular hypertension. Our data indicate that the changes in plasma renin activity and angiotensin II are due to changes in the amount of the renin rather than to changes in other elements of the renin-angiotensin system.— renin; angiotensin; hypertension; furosemide
\end{abstract}

Since primary aldosteronism is a syndrome characterized by sodium retention resulting in an increase of extracellular volume, the renin-angiotensin system should be suppressed according to the recent concept of renin-angiotensin system. On the other hand, the decrease in renal perfusion pressure or renal circulating blood volume observed in renovascular hypertension, causes an increase of renin-angiotensin system. Many researchers have already reported the plasma renin activity measured by bioassay in various kinds of hypertension. However, the bioassay method requires a very long time and complicated technique which can be proceeded only in well-facilitated laboratories. Furthermore, plasma angiotensin II can not be estimated by the bioassay method because of low concentration of angiotensin II in

Received for publication, February 19, 1973.

Director: Prof. T. Torikai 
plasma. The development of radioimmunoassay made it possible to estimate easily both plasma renin activity and plasma angiotensin II concentration in hypertensive patients under rapidly controlled hospital conditions. In this report the changes of plasma renin activity and plasma angiotensin II were measured by radioimmunoassay before and after 2-hour upright position and furosemide administration in hypertensive patients of various origins.

\section{Materials and Methods}

Sixteen cases of primary aldosteronism, 7 of Cushing's syndrome, one of which was caused by adrenal adenoma, 33 of essential hypertension, 26 of renovascular hypertension, and 15 of chronic glomerulonephritis, were studied. All of primary aldosteronism were caused by adrenal adenoma, two of which were normokalemic cases. Twelve cases of renovascular hypertension were due to unilateral renal artery stenosis and 14 due to bilateral renal artery stenosis. All patients were placed on regular diet containing approximately $250 \mathrm{mEq}$ of sodium. Diuretic drugs were withdrawn for at least 2 weeks before estimation. Blood was drawn from cubital vein for plasma renin activity and from femoral artery for plasma angiotensin II, with the syringe containing $0.1 \mathrm{ml}$ of $8.0 \%$ EDTA disodium in recumbent state before breakfast early in the morning. Plasma renin activity and angiotensin II were also measured, after the pitients were administered intravenously $40 \mathrm{mg}$ of furosemide and placed on upright position for 2 hours.

Plasma renin activity was measured by radioimmunoassay of angiotensin I generated by the incubation of plasma at $\mathrm{pH} 5.5$ (Fukuchi et al. 1973). Plasma angiotensin II was measured by radioimmunoassay after the separation by Dowex 50W-X4 column (Fukuchi and Katsushima 1971).

\section{Results}

Plasma renin activity and plasma angiotensin II in normal subjects and hypertensive patients

Plasma renin activity in 21 normal subjects was from 0.12 to $3.00 \mathrm{ng} / \mathrm{ml} / \mathrm{hr}$, mean 1.07 with a standard deviation of 0.90 . For normal subjects, plasma angiotensin II ranged from 18 to $106 \mathrm{pg} / \mathrm{ml}$, average $53.2 \mathrm{pg} / \mathrm{ml}$ with a standard deviation of 29.3. Plasma renin activity and angiotensin II closely paralleled each other.

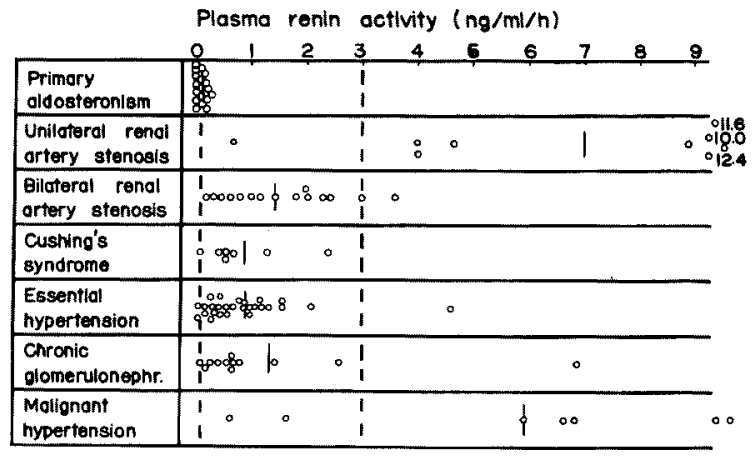

Fig. 1. Plasma renin activity in hypertensive patients. Dotted lines show the normal range. Means are indicated by vertical bars. 


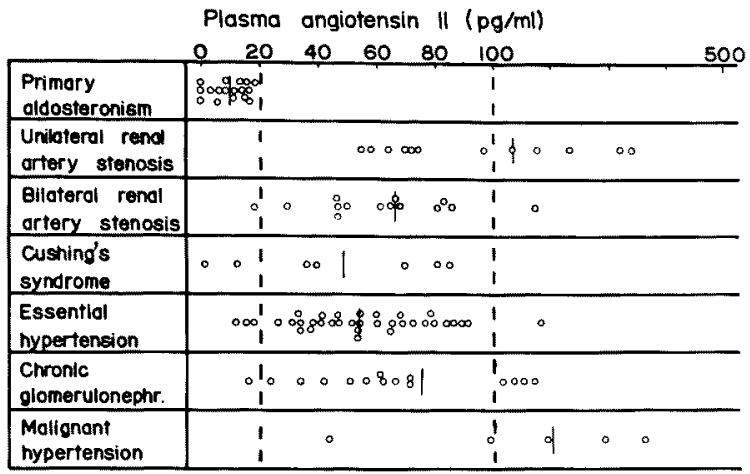

Fig. 2. Plasma angiotensin II in hypertensive patients. Dotted lines show the normal range. Means are indicated by vertical bars.

As shown in Figs. 1 and 2 , in primary aldosteronism, plasma renin activity was low, ranging from 0 to $0.28 \mathrm{ng} / \mathrm{ml} / \mathrm{hr}$, average 0.10 with a standard deviation of $0.09 \mathrm{ng} / \mathrm{ml} / \mathrm{hr}$, which rose to $0.08-1.80(0.74 \pm 0.61) \mathrm{ng} / \mathrm{ml} / \mathrm{hr}$ after the removal of adrenal adenoma. Plasma angiotensin II was $0-18(10.7 \pm 6.6) \mathrm{pg} / \mathrm{ml}$, which increased to $6-85(38.3 \pm 20.3) \mathrm{pg} / \mathrm{ml}$ after the surgery. Of 26 cases of renovascular hypertension, 12 cases with unilateral renal artery stenosis showed a high value of $7.10 \pm 4.00 \mathrm{ng} / \mathrm{ml} / \mathrm{hr}$ in plasma renin activity, and $134.5 \pm 96.5 \mathrm{pg} / \mathrm{ml}$ in plasma angiotensin II, which were lowered after the correction of renal circulation. On the other hand, plasma renin activity and plasma angiotensin II in 16 cases of bilateral renal artery stenosis showed a normal value of $1.44 \pm 1.00 \mathrm{ng} / \mathrm{ml} / \mathrm{hr}$ and $66.1 \pm 38.6 \mathrm{pg} / \mathrm{ml}$, respectively. Both plasma renin activity and angiotensin II slightly decreased after the surgery. In Cushing's syndrome, both plasma renin activity and plasma angiotensin II showed a normal value of $0.13-2.40(0.88 \pm$ $0.70) \mathrm{ng} / \mathrm{ml} / \mathrm{hr}$ and $6-85(48.0 \pm 29.1) \mathrm{pg} / \mathrm{ml}$, respectively. Also in essential hypertension, normal values of $0.89 \pm 0.89 \mathrm{ng} / \mathrm{ml} / \mathrm{hr}$ in plasma renin activity and of $54.9 \pm 23.3 \mathrm{pg} / \mathrm{ml}$ in plasma angiotensin II were observed. In chronic glomerulonephritis, plasma renin activity and plasma angiotensin II elevated slightly to $1.30 \pm 1.79 \mathrm{ng} / \mathrm{ml} / \mathrm{hr}$ and $74.8 \pm 44.7 \mathrm{pg} / \mathrm{ml}$, respectively.

Plasma renin activity and angiotensin II upon upright position and furosemide administration

In normal subjects, plasma renin activity and angiotensin II raised from $1.45 \pm 0.13$ to $3.70 \pm 1.70 \mathrm{ng} / \mathrm{ml} / \mathrm{hr} \quad(\mathrm{n}=8, .01<\mathrm{p}<.025)$ and from $48.0 \pm 12.0$ to $65.0 \pm 11.0 \mathrm{pg} / \mathrm{ml}(\mathrm{n}=8, \mathrm{p}<.005)$, respectively, upon upright position and furosemide administration. As can be seen from Figs. 3 and 4, plasma renin activity increased slightly from $0.11 \pm 0.09$ to $0.25 \pm 0.16 \mathrm{ng} / \mathrm{ml} / \mathrm{hr}$ on upright posture after furosemide administration $(\mathrm{n}=9, .025<\mathrm{p}<.05)$ in primary aldosteronism. Plasma angiotensin II also slightly increased from $11.4 \pm 6.1$ to $21.9 \pm 8.5 \mathrm{pg} / \mathrm{ml}(\mathrm{n}=11$, $.025<\mathrm{p}<.05$ ). After the removal of adrenal adenoma, the combined stimuli of 


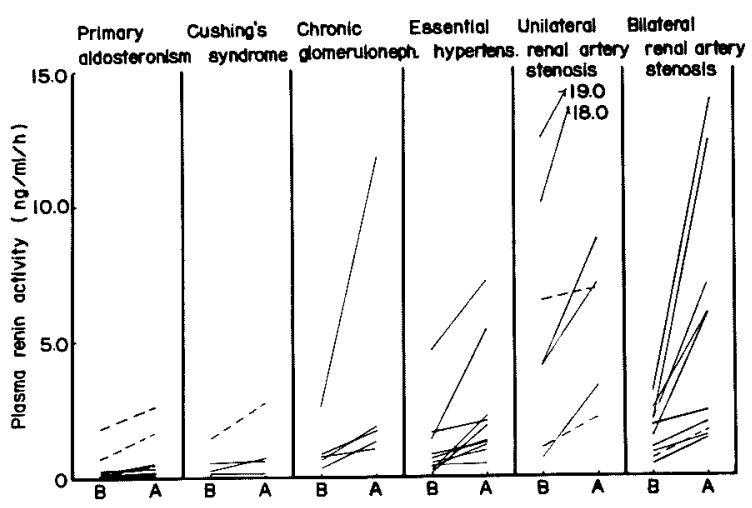

Fig. 3. Effects of upright position and furosemide administration on plasma renin activity in hypertensive patients. Dotted lines show the values of plasma renin activity after surgery.

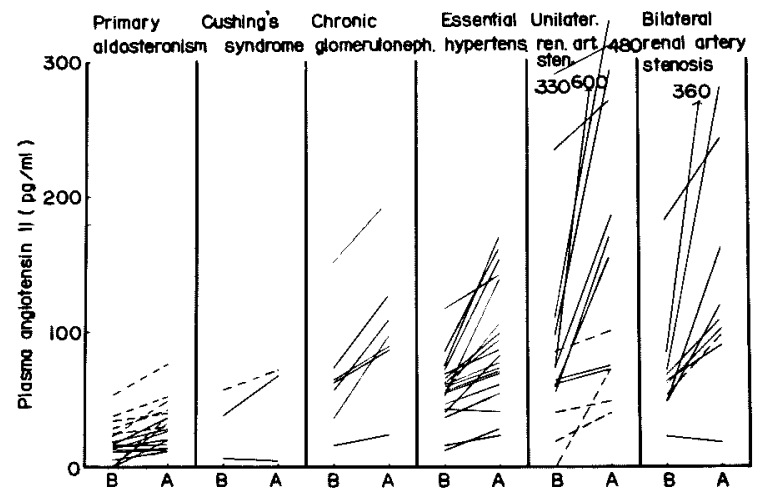

Fig. 4. Effects of upright position and furosemide administration on plasma angiotensin II in hypertensive patients. Dotted lines show the values of plasma angiotensin II after surgery.

upright posture and furosemide administration increased plasma renin activity from $0.66 \pm 0.71$ to $1.25 \pm 0.93 \mathrm{ng} / \mathrm{ml} / \mathrm{hr} \quad(\mathrm{n}=4, .025<\mathrm{p}<.05)$. Plasma angiotensin II raised from $28.6 \pm 15.0$ to $35.7 \pm 14.0 \mathrm{pg} / \mathrm{ml} \quad(\mathrm{n}=8, \mathrm{p}<.005)$. In 3 cases of Cushing's syndrome, the change in plasma renin activity was very little, from $0.34 \pm 0.21$ to $0.40 \pm 0.26 \mathrm{ng} / \mathrm{ml} / \mathrm{hr}(\mathrm{n}=3, \mathrm{p}>.1)$. Angiotensin II did not appreciably respond to this stimulus $(22.5 \pm 16.5$ to $36.5 \pm 31.5 \mathrm{pg} / \mathrm{ml}, \mathrm{n}=2, \mathrm{p}>.1)$. In chronic glomerulonephritis, plasma renin activity increased slightly from $1.00 \pm 0.82$ to $3.27 \pm 4.18 \mathrm{ng} / \mathrm{ml} / \mathrm{hr}(\mathrm{n}=5, \mathrm{p}>.1)$, and plasma angiotensin II increased from $64.6 \pm$ 39.2 to $103.4 \pm 47.6 \mathrm{pg} / \mathrm{ml}(\mathrm{n}=7, \mathrm{p}<.005)$. In essential hypertension, plasma renin activity increased from $1.04 \pm 1.27$ to $2.34 \pm 2.08 \mathrm{ng} / \mathrm{ml} / \mathrm{hr}(\mathrm{n}=10, .01<\mathrm{p}<.025)$, and angiotensin II from $57.3 \pm 24.0$ to $93.6 \pm 43.5 \mathrm{pg} / \mathrm{ml}(\mathrm{n}=19, \mathrm{p}<.005)$. In unilateral renal artery stenosis, plasma renin activity increased markedly from $5.97 \pm 4.17$ to $11.16 \pm 6.27 \mathrm{ng} / \mathrm{ml} / \mathrm{hr}(\mathrm{n}=5, .0 \mathrm{l}<\mathrm{p}<.025)$, and angiotensin II from $114.8 \pm 88.0$ to $262.3 \pm 162.8 \mathrm{pg} / \mathrm{ml}(\mathrm{n}=10, .01<\mathrm{p}<.025)$. In postoperative cases, the renin activity 


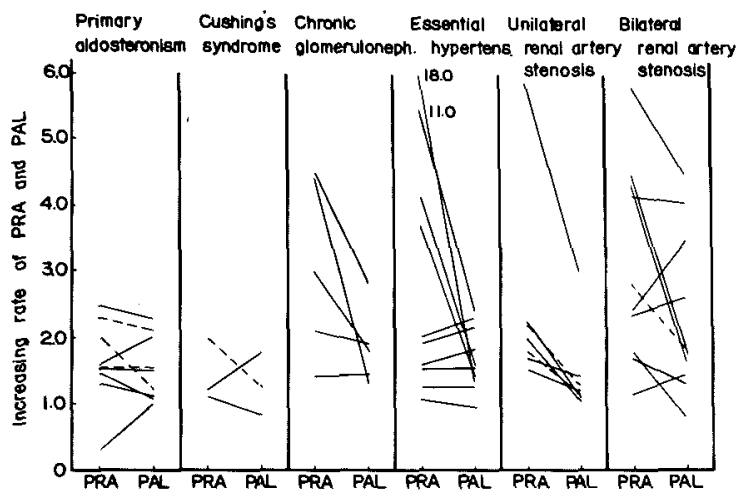

Fig. 5. Increase in plasma renin activity (PRA) and plasma angiotensin II level (PAL) after upright position and furosemide administration in hypertensive patient.

and angiotensin II increased from $3.70 \pm 2.70$ to $4.55 \pm 2.35 \mathrm{ng} / \mathrm{ml} / \mathrm{hr}(\mathrm{n}=2, \mathrm{p}>.1$ ), and from $35.5 \pm 31.4$ to $65.0 \pm 23.4 \mathrm{pg} / \mathrm{ml}(\mathrm{n}=4, \mathrm{p}>.1)$, respectively, upon upright position and furosemide administration, but these changes were not significant. In bilateral renal artery stenosis, plasma renin activity increased slightly from $1.64 \pm$ 0.79 to $5.33 \pm 4.16 \mathrm{ng} / \mathrm{ml} / \mathrm{hr}(\mathrm{n}=9, .01<\mathrm{p}<.025)$, and plasma angiotensin II from $70.4 \pm 42.0$ to $163.8 \pm 102.2 \mathrm{pg} / \mathrm{ml}(\mathrm{n}=9, .01<\mathrm{p}<.025)$.

As shown in Fig. 5, the increase in plasma renin activity upon upright position and furosemide administration was larger than corresponding increase in circulating angiotensin II.

The change of plasma renin activity and angiotensin II after the removal of adrenal adenoma in primary aldosteronism

Renin and angiotensin II in plasma showed a low value during 3 weeks after surgery, which was followed by an increase to normal value (Figs. 6 and 7). But

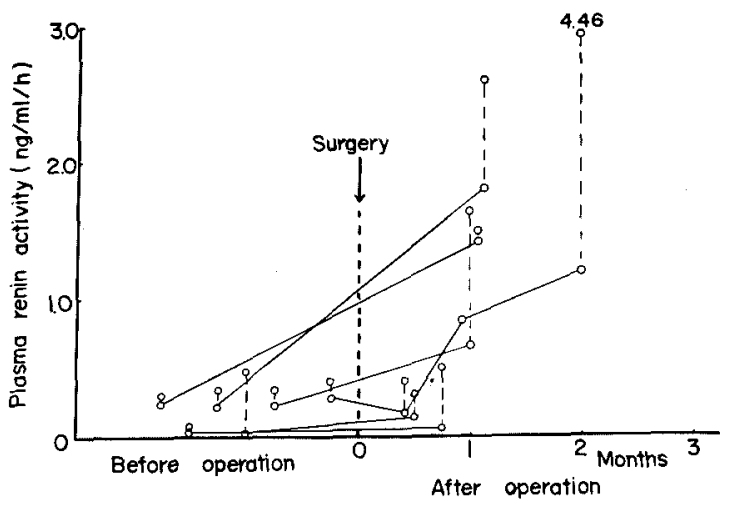

Fig. 6. Changes of plasma renin activity before and after the removal of adrenal adenoma in primary aldosteronism. Vertical dotted lines show the increase of plasma renin activity with upright position and furosemide administration. 


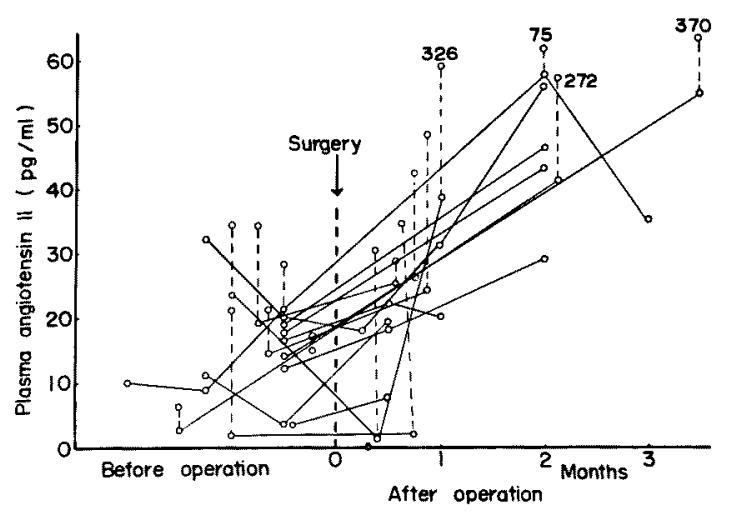

Fig. 7. Changes of plasma angiotensin II before and after the removal of adrenal adenoma in primary aldosteronism. Vertical dotted lines show the increase of plasma angiotensin II with upright position and furosemide administration.

they responded normally to the combined stimuli of upright position and furosemide administration even when the renin-angiotensin system was suppressed 3 weeks after surgery.

\section{Discussion}

Conn (1964) reported that in the presence of an aldosterone-secreting tumor, plasma renin activity is suppressed to zero, and it cannot be increased above zero even after many days of severe sodium deprivation. The suppression of renal release of renin in primary aldosteronism is not due to a high blood level of aldosterone per se, but rather to the increase in intravascular volume and pressure which is known to be associated with the increased production of aldosterone. The combination of overproduction of aldosterone and suppression of plasma renin activity is uniquely diagnostic of an aldosterone-secreting cortical tumor.

The present study showed the suppression of both plasma renin activity and angiotensin II which did not rise after the combined stimuli of upright and furosemide administration in primary aldosteronism. However, since low values of plasma renin activity and plasma angiotensin II were also observed in some cases of other hypertensive diseases, the stimulating procedure is indefinitely valuable for differential diagnosis of primary aldosteronism. The suppression was found not only in hypokalemic, but also in normokalemic primary aldosteronism. This fact indicates that the low plasma renin activity in this disease was not due to low serum potassium.

In primary aldosteronism, plasma renin activity and angiotensin II rapidly restored a normal value within 4 weeks after surgery, and responded to upright posture and furosemide administration as well as in essential hypertension. Shishito and Watanabe (1971) stated that a remarkable loss of both sodium and potassium was observed during a few days after removal of the adrenal tumor in the majority of the cases and a restoration of proper electrolyte regulation mechan- 
ism was achieved only during the second postoperative week. In this experiment a low response of plasma renin activity to furosemide administration and upright position was observed in a stage of low renin activity 2 weeks after the removal of adrenal adenoma.

The high concentration of renin and angiotensin II in plasma found in renovascular hypertension, is assumed to be due to the decrease in renal blood flow. The fact that renin-angiotensin is markedly increased in unilateral renal artery stenosis and slightly in bilateral stenosis, suggests that the increase is related to the difference of renal perfusion pressure between both renal arteries. Whereas, renin and angiotensin II in plasma increased markedly after upright position and furosemide administration in most cases of both unilateral and bilateral renal artery stenosis. After the correction of renal circulation, the response of renin and angiotensin to the upright position and furosemide administration was much less as compared with that in other hypertensive diseases.

Renin-angiotensin in Cushing's syndrome was also found to be suppressed through the electrolyte effect of hydrocortisone, showing no response to upright posture and furosemide administration. In essential hypertension renin-angiotensin system showed a low average, which was probably caused by the rise in renal perfusion pressure or the increase in circulating blood volume. The patients with essential hypertension in this study were all benign type without renal or cardiac complication. However, upright position and furosemide administration induced a marked increase of renin activity and angiotensin II. The finding shows no existence of definite suppression of renin-angiotensin system. In a few cases of chronic glomerulonephritis, both renin and angiotensin were slightly increased, but not in most of them. The normal response of renin-angiotensin was observed after the upright and furosemide administration in chronic glomerulonephritis.

Renin is released from the juxtaglomerular apparatus by changes in flow, or pressure, or both in renal blood perfusion. Then through a series of reactions, angiotensin II is generated. Angiotensin II acts on adrenal receptor sites to increase aldosterone secretion and thereby causes sodium retention. Many other factors may play a role in this feedback loop, but renin and angiotensin II appear to be the major components.

The results obtained in the present study could be explained by one or more of four defects, partial or complete, in renin-aldosterone volume feedback loop. First, there could be a blunting of renin release per unit of volume depletion in patients with primary aldosteronism thus requiring a greater degree of depletion in order to increase the plasma renin activity. The present study supports such a hypothesis.

The demonstration (Cohen et al. 1967) that renin substrate does not change significantly upon assumption of the upright posture rules out the possibility that the increase of renin substrate may be responsible to the elevation of the renin activity.

A third possibility is that there is a defect in the enzyme which converts 
angiotensin I to angiotensin II. The present study demonstrates that there is an excellent correlation between plasma renin activity and plasma angiotensin II upon standing and furosemide administration while on a normal diet. It would therefore appear unlikely that our hypertensive patients had a defect in the converting enzyme.

A more rapid destruction of angiotensin in the hypertensive could also produce this result. This could occur if there were increased levels of angiotensinase or a defective circulating angiotensin molecule that was more susceptible to destruction. Hickler and co-workers (1963) have demonstrated that there are increased angiotensinase levels in the plasma of hypertensives complicated with moderately severe to severe cardiovascular disease. However, they could not find any increase in the levels in patients with mild or labile hypertension. Increased angiotensinase levels do not appear to account for the observed results.

In the present study, patients with primary aldosteronism exhibited greatly suppressed levels of plasma renin activity and angiotensin II under the conditions of upright position and furosemide administration, while normal persons well responded to these stimuli, showing very high levels of plasma renin activity and angiotensin II. Suppression of reactivity of plasma renin activity and plasma angiotensin II is characteristic to and is diagnostic of an aldosterone-producing adrenal tumor. Furthermore, we may take advantage of the enhancing effect of upright position on plasma in diagnosis of renovascular hypertension.

\section{References}

1) Cohen, E.L., Conn, J.W. \& Rovner, D.R. (1967) Postural augmentation of plasma renin activity and aldosterone excretion in normal people. J. clin. Invest., 46, 418428.

2) Conn, J.W. (1964) Plasma renin activity in primary aldosteronism. J. Amer. med. Ass., $190,222-225$.

3) Fukuchi, S. \& Katsushima, I. (1971) Measurement of plasma angiotensin II by radioimmunoassay. Tohoku J. exp. Med., 103, 185-193.

4) Fukuchi, S., Takenouchi, T. \& Torikai, T. (1973) Determination of plasma renin activity by radioimmunoassay of angiotensin I. Clin. Sci., 44, 43-54.

5) Hickler, R.B., Lauler, D.P. \& Thorn, G.W. (1963) Plasma angiotensinase activity in patients with hypertension and edema. J. clin. Invest., 42, 635-648.

6) Shishito, S. \& Watanabe, H. (1971) Postoperative course and treatment in adrenal surgery. Urol. Intern., 26, 1-12. 